\title{
LEITURA FENOMENOLÓGICA DA RELIGIOSIDADE: IMPLICAÇÕES PARA O PSICODIAGNÓSTICO E PARA A PRÁXIS CLÍNICA PSICOLÓGICA
}

\author{
Phenomenological Approach of Religiosity: \\ Implications for Psychodiagnostic and Psychological Clinic Praxis \\ Leitura Fenomenologica de la Religiosidad: \\ Implicaciones para el Psicodiagnostico y la Praxis Clínica Psicológica
}

Marta Helena DE FReitas

Paula Rey Vilela

\begin{abstract}
Resumo: Este trabalho tem como objetivo apontar, discutir e ilustrar algumas contribuições da fenomenologia com vistas a uma apreciação crítica dos critérios de psicodiagnóstico de experiências religiosas e suas possíveis conexões ou distinções com os sintomas ou quadros clínicos psicopatológicos. Especial atenção será dada àqueles que envolvem o delírio religioso, o qual tem sido frequentemente apontado em certas interpretações de fenômenos religiosos no Brasil, mormente daqueles que se fazem presentes em diversos movimentos messiânicos no país. Para tanto, após alguns esclarecimentos conceituais relevantes, discutindo as conexões e distinções entre espiritualidade, religiosidade e religião, busca-se ancoragem nos princípios fundamentais da fenomenologia husserliana, como também nas contribuições posteriores de Merleau-Ponty e Karl Jaspers, colocando-os em diálogo com as concepções pragmáticas de William James. Toma-se o caso específico de um líder messiânico no Brasil, Mestre Yokaanam, com vistas a ilustrar as implicações da leitura fenomenológica aqui proposta.
\end{abstract}

Palavras chave: Fenomenologia; Religiosidade; Psicodiagnóstico.

Abstract: This paper aims to highlight, discuss and illustrate the contributions that phenomenology can offer for critically assessing criteria for the psychological diagnosis of religious experiences and their possible connection with or distinctions from psychopathological symptoms or clinical conditions. Especial attention is given to those experiences involving religious delusion because they have been often singled out in interpretations of religious phenomena in Brazil, especially in messianic movements. After putting forward a conceptual clarification and discussion of the connections and distinctions between spirituality, religiosity and religion, the paper presents the fundamental philosophical principles of Husserl's phenomenology and the later contributions of Merleau-Ponty and Karl Jaspers, putting them in dialogue with the pragmatic conceptions of William James. Focusing on the specific case of a messianic leader in Brazil, Master Yokaanam, the paper illustrates the implications of the phenomenological reading proposed here.

Keywords: Phenomenology; Religiosity; Psychodiagnostic.

Resumen: El presente trabajo tiene como objetivo señalar, discutir e ilustrar algunas contribuciones de la fenomenología con miras a una apreciación crítica de los criterios para el psicodiagnóstico de las experiencias religiosas, así como sus posibles conexiones o diferenciaciones con síntomas o cuadros clínicos psicopatológicos. Se prestó especial atención a las experiencias que involucran el delirio religioso, el cual se menciona a menudo en algunas interpretaciones de fenómenos religiosos en Brasil, especialmente los que están presentes en diversos movimientos mesiánicos en el país. Para este fin, después de algunas aclaraciones conceptuales relevantes, y discutiendo las conexiones y diferencias entre la espiritualidad, la religiosidad y la religión, se tomaron como base los principios fundamentales de la fenomenología de Husserl al igual que los aportes posteriores de Merleau-Ponty y Karl Jaspers, poniéndolos en diálogo con las concepciones pragmáticas de William James. Se presenta el caso específico de un líder mesiánico en Brasil, el Maestro Yokaanam, con el fin de ilustrar las implicaciones de la lectura fenomenológica aquí propuesta.

Palabras clave: Fenomenología; Religiosidad; Psicodiagóstico.

\section{Introdução}

Uma pergunta é colocada frequentemente pelo/a estudante de psicologia, no Brasil, ao iniciar seus estudos em Psicopatologia: como distinguir se uma experiência é de cunho religioso/espiritual ou apenas um sintoma psicopatológico? Embora nem sempre esta pergunta seja formulada explicitamente em sala de aula, muitas vezes com receios de ser criticado/a pelos professores ou pe- los próprios colegas, o/a jovem estudante de psicologia a formula intimamente ou verbaliza entre aqueles/as com quem se sente mais a vontade para falar sobre o assunto. E, mais tarde, ao realizar a experiência de estagiário em saúde mental, a pergunta pode lhe retornar novamente, em contextos ainda mais complexos, pois agora não se trata apenas de um conteúdo teórico a ser apreendido numa disciplina, mas de uma ação concreta de sua parte, seja na emissão de um psicodiagnóstico, seja na natureza do 
encaminhamento ou condução da questão que lhe é levada pelo usuário do serviço onde desenvolve o seu estágio.

Sabe-se que a questão em torno das possíveis conexões e distinções entre o fenômeno religioso e o fenômeno psicopatológico esteve presente nas preocupações dos estudiosos em psicologia desde o seu início - ou melhor, desde a sua pré-história - e foi objeto de estudo e reflexão daqueles que a fundaram, embora isso, na maioria das vezes, nem chegue ao conhecimento do/a jovem estudante. A omissão desta realidade aponta, dentre outras coisas, a grande dificuldade dos professores em abordar um tema muito suscetível de mobilizações diversas e que é frequentemente tomado como não relevante para um conhecimento que se pretenda científico. Muito embora se observe, nas duas últimas décadas, uma retomada do tema, com aumento considerável no número de publicações no campo que se convencionou chamar "psicologia da religião", e isso tenha contribuído para que o tema seja hoje abordado com mais naturalidade em aula, pode-se afirmar que o "cala boca” e a discriminação contra o assunto ainda não morreu, conforme atestam depoimentos recentes de psicólogos que atuam em hospitais e serviços de saúde mental, quando se referem à sua formação (Freitas, 2015).

Se uma das propostas da fenomenologia - da qual Brentano (1838-1917) foi o precursor e Husserl (18591938), o seu fundador - é justamente o de "retorno às coisas mesmas” e respectiva qualificação do mundo da vida tal como ele se dá em ato, como esta perspectiva pode contribuir para a mudança deste cenário de silenciamento e marginalização? E, neste caso, como ela pode ajudar estudantes e profissionais no seu percurso de buscar respostas para questões relacionadas ao tema da religiosidade e suas relações com saúde mental? Pode esta perspectiva oferecer instrumentos para um manejo adequado e ético da religiosidade trazida pelo usuário em situações clínicas, a qual muitas vezes é vivida pelo profissional em psicologia como algo que efetivamente "atravessa" o seu trabalho? Se sim, como? Em que e como esta perspectiva pode lhe ser útil na realização do psicodiagnóstico diferencial, quando este se faz necessário, e quais as implicações sobre prognósticos, encaminhamentos e acompanhamentos clínicos?

Mobilizadas pelas questões acima, buscaremos neste artigo, identificar algumas contribuições da leitura fenomenológica da experiência religiosa e suas respectivas relações com fenômenos descritos como psicopatológicos, mormente a questão do delírio religioso, frequentemente apontado em variadas interpretações de fenômenos religiosos no Brasil, incluindo-se aí aqueles que se fazem presentes nos diversos movimentos messiânicos no país. Para tanto, buscaremos ancoragem nos princípios fundamentais da fenomenologia, desde o conceito de intencionalidade, inaugurado por Brentano, e sua retomada por Husserl, seu fundador, como também nas contribuições posteriores de Merleau-Ponty (1908-1961), colocando-as em diálogo com as concepções da psicopatologia com- preensiva de Karl Jaspers (1883-1969) e as concepções pragmáticas de William James (1842-1910). A escolha destes autores se justifica pelo fato de propiciarem uma perspectiva mais integradora entre diferentes níveis da experiência humana, em vez de reproduzirem um modelo reducionista, pautado na mera dissociação entre racionalidade e crença, afeto e cognição, patologia e normalidade.

A escolha aqui apontada é, portanto, de cunho ético e epistemológico. E, naturalmente, reflete o viés destas autoras que, em pesquisas recentes, têm empregado tais referenciais para repensar a prática do profissional de saúde - dentre eles o psicólogo - nos contextos das reformas sanitária e psiquiátrica. Em especial, nos Centros de Atenção Psicossocial - CAPs, os quais devem contar com os recursos disponíveis no território onde estão localizados, incluindo-se aí aqueles oferecidos pelas muitas e diversas comunidades e instituições religiosas presentes em todas as regiões do país.

\section{Iniciando com alguns esclarecimentos conceituais}

A complexidade no terreno da chamada Psicologia da Religião se inicia pela dificuldade em conceituar fenômenos de natureza religiosa. Como bem lembra Baltazar (2003), alguém já disse que religiosidade é algo que se compreende bem até o momento em que se resolve defini-la. Portanto, do ponto de vista fenomenológico, o primeiro cuidado a ser tomado é o de que, ao procurar fazer esclarecimentos epistemológicos e conceituais necessários para a devida compreensão do assunto, não se incorra no mero esvaziamento do próprio fenômeno, a ponto de fazê-lo perder-se completamente de vista.

Uma porção de termos são empregados neste campo e foge aos propósitos deste capítulo nos referirmos a todos eles. Mas cabem alguns esclarecimentos sobre o que estamos aqui chamando de religiosidade, apontando também suas intrínsecas relações com dois outros conceitos que lhe são correlatos: espiritualidade e religião. Buscaremos fazer isso sem os retirar do âmbito em que são experimentados existencialmente pelas pessoas, de carne e osso, no seu contexto de vida.

Reproduziremos aqui uma definição descrita anteriormente em outro trabalho, onde uma de nós (Freitas, 2012, p. 199) emprega o termo religiosidade para se referir àquelas disposições humanas que levam à pessoa a experimentar fenômenos religiosos. Embora, a princípio, esta definição possa parecer tautológica, ela tem o mérito de legitimar a experiência, remetendo-nos ao sentido original do termo alemão Erlebnis, conforme aponta Valle (1998). Em outras palavras, a religiosidade é algo experimentado desde o âmago de si mesmo - ainda que sem excluir o que está fora, dotado de profunda imediaticidade em termos de sentimento, ainda que acompanhada de intensa elaboração do pensamento - e portadora de sentido e valor evidentes em si mesmos para o próprio sujeito que assim a vivencia”. 
Segundo Aletti (2012), muitos autores têm preferido o termo espiritualidade para se referir à dimensão psicológica, baseada em experiências subjetivas e emoções, buscando fazer referência a um processo mais genérico, e provavelmente universal, que movimenta o homem na direção da "busca de sentido". Este termo, por sua vez, tem sido frequentemente empregado para fazer oposição ao conceito de religião, quando se toma está última como voltada para o aspecto institucional, caracterizando uma dimensão mais estática, ancorada à tradição, ao dogma e à doutrina que apresenta uma concepção simultaneamente moral e normativa.

De uma perspectiva fenomenológica, esta polarização entre os dois conceitos é vista como tendo um caráter reducionista, ao invés de propulsor à compreensão mais genuína da experiência em causa. Isso porque uma pessoa, em geral, está justamente movida por este impulso pela busca de sentido ao filiar-se a uma instituição religiosa. Esta pode se caracterizar, naquele momento, como uma possível resposta, uma forma de atender justamente à demanda de sentido existencial. Afinal, no decorrer da história da humanidade, tem sido justamente o compartilhamento destas possíveis respostas para esta demanda de sentido o que, em conexão com outros aspectos socioculturais, embora também políticos, fazem originar a religião enquanto sistema coletivo de crenças.

Ressaltamos, então, que, segundo o aporte fenomenológico, a espiritualidade é definida nos moldes em que nos ensina Husserl (1936/2008), voltando-se "exclusivamente para os homens enquanto pessoas e para sua vida e realizações pessoais, bem como, correlativamente, para as figuras dessas realizações". Ora, isso implica necessariamente na capacidade de reflexão sobre si mesmo, bem como sobre sua experiência junto ao mundo circundante, tanto no sentido horizontal, na sua relação com outros homens, como no sentido vertical, na sua abertura a uma dimensão que o transcende, a qual pode ser caracterizada por ele mesmo como sendo de âmbito religioso ou não. Ou seja, aquilo que o impulsiona em direção à busca de sentido pode ou não encontrar resposta no ponto irredutível da experiência religiosa. Desta perspectiva, a espiritualidade é, portanto, pelo menos do ponto de vista lógico, uma experiência anterior à da religiosidade e esta última, por sua vez, simultaneamente anterior e/ou posterior à religião. $\mathrm{O}$ conceito de religião fica então reservado para se referir a uma modalidade de resposta compartilhada e que assume, como o refere Amatuzzi (2001, p. 32), a forma de uma

[...] organização externa, mais ou menos coerente, de crenças, valores, mitos e ritos que giram em torno de um enfoque da questão do último, e que frequentemente corresponde à existência histórica de um corpo social hierarquizado ao qual algumas pessoas dão a sua adesão.

A partir do exposto, elaboramos uma figura que busca ilustrar o lugar ocupado pela religiosidade e suas relações com a espiritualidade e a religião, conforme a seguir.

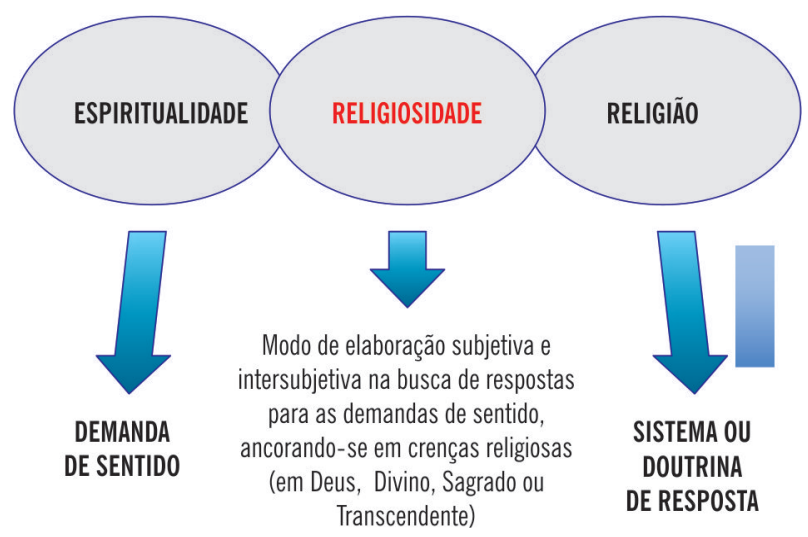

Figura 1: Concepção de religiosidade.

Este modo de definir a religiosidade é pleno de implicações para atuação do psicólogo, na medida em que o estimula a não repetir tendência frequentemente encontrada nos depoimentos sobre o assunto: aquela que tende a associar espiritualidade a uma dimensão saudável e religião a uma dimensão patológica, como se viu com frequência em depoimentos de profissionais entrevistados no contexto da saúde mental (Freitas, 2012; 2013). Ao mesmo tempo, ela o permite descobrir uma forma de avaliar, junto ao próprio usuário, o que em sua própria forma de responder às demandas de sentido existencial está legitimamente ancorado numa religião ou está apenas sendo "sufocado" ou pelo menos "moldado" pela imposição de um sistema de respostas não genuinamente acreditado ou creditado por ele próprio.

Por outro lado, o modelo proposto permite qualificar tanto a singularidade quanto a diversidade no encontro de respostas às demandas de sentido existencial, sejam eles ancorados ou não num sistema coletivo de crenças compartilhadas. Ao reconhecer isto, o terapeuta poderá buscar identificar, junto ao seu paciente, o quanto o seu próprio sistema de crenças foi ou não abraçado às custas da inibição da sua capacidade reflexiva sobre si mesmo e/ou sobre o mundo em que se situa.

O modelo permite, ainda, evitar que o exame desta capacidade reflexiva se reduza apenas ao nível da racionalidade, preservando o espaço para a dimensão intuitiva e pré-reflexiva. Visando elucidar melhor esta perspectiva, buscaremos no próximo item recorrer a algumas contribuições do próprio Husserl e também de Merleau-Ponty.

\section{Recuperando operações que nos põem em relação genuína com o outro}

A concepção pautada no modelo médico adotado pela psicopatologia, no seu esforço de catalogação das chamadas "doenças mentais", presume que a relação da mente com o mundo é dada, e que os delírios, dentre eles os religiosos, por exemplo, podem ser identificados a partir de sua falsidade, incorrigibilidade e certeza. Ocorre que esta concepção exige uma distinção supostamente objetiva 
entre o que é falso e verdadeiro, tendo como parâmetro o julgamento via percepção externa, nos moldes em que se sustenta o modelo científico que vingou no contexto ocidental. Este modelo gerou também uma série de critérios, baseados na forma e no conteúdo do fenômeno observado, visando possibilitar a distinção e o diagnóstico diferencial entre o que se poderia chamar de experiência psicótica e experiência espiritual genuína, sistematizados por Jackon e Fuldord (1997, p. 43) conforme ilustra a Tabela 1.

Tabela 1: Distinção entre experiência espiritual e psicose segundo a psicopatologia clássica.

\begin{tabular}{l|l}
\hline \multicolumn{1}{c|}{ Experiência Espiritual } & \multicolumn{1}{c}{ Psicose } \\
\hline $\begin{array}{l}\text { Ortodoxia doutrinária - con- } \\
\text { teúdo aceitável pelo grupo } \\
\text { subcultural }\end{array}$ & $\begin{array}{l}\text { Conteúdo bizarro - particularmente } \\
\text { acompanhado de reivindicações de } \\
\text { status divino ou poderes especiais }\end{array}$ \\
\hline $\begin{array}{l}\text { Elementos sensoriais são "in- } \\
\text { telectuais" (experimentados } \\
\text { como conteúdo mental) }\end{array}$ & $\begin{array}{l}\text { Elementos sensoriais são “corporais" } \\
\text { (experimentados como percepções } \\
\text { verídicas) }\end{array}$ \\
\hline $\begin{array}{l}\text { Alucinações predominante- } \\
\text { mente visuais }\end{array}$ & $\begin{array}{l}\text { Alucinações predominantemente } \\
\text { auditivas }\end{array}$ \\
\hline $\begin{array}{l}\text { Crenças formadas com pos- } \\
\text { sibilidade de dúvida. Insight } \\
\text { presente }\end{array}$ & Crenças incorrigíveis. Insight ausente \\
\hline Duração breve & Duração estendida \\
\hline $\begin{array}{l}\text { Controle voluntário sobre as } \\
\text { experiências }\end{array}$ & Experiências são involuntárias \\
\hline Orientada para o outro & Auto orientada \\
\hline $\begin{array}{l}\text { Auto atualizadora”; potencia- } \\
\text { lizadora de vida; frutos es- } \\
\text { pirituais }\end{array}$ & $\begin{array}{l}\text { Desintegradora; deterioração no fun- } \\
\text { cionamento da vida. }\end{array}$ \\
\hline
\end{tabular}

(Reproduzido e adaptado de Jackson e Fulford, 1997, p. 43).

Os próprios autores que sistematizaram o conteúdo da tabela acima avaliam, entretanto, que as distinções entre experiência espiritual e psicopatológica aí apontadas, e que estão na base da elaboração das proposições para diagnósticos diferenciais contemplados nos manuais de psicopatologia - como, por exemplo, o DSM - não se apoiam somente em fatos científicos objetivos, mas envolvem também julgamentos de valor. Pautando-se sobre uma perspectiva cognitivista, os autores mostram como que a distinção aí pretendida depende, antes, da maneira pela qual os próprios "fenômenos psicóticos" estão inseridos nos valores e crenças da pessoa envolvida, com importantes implicações tanto para o diagnóstico, como para o tratamento e para a investigação em psicopatologia.

De fato, se fôssemos adotar ao pé da letra os critérios relacionados no referido quadro, correríamos o risco de classificarmos como psicóticos todos os fundadores das chamadas seitas messiânicas em nosso país, dentre eles: Antônio Conselheiro, em Canudos; Padre Cícero, em Juazeiro; Jacobina Mentz, em Sapiranga; Mestre Yokaanam, em Anápolis e Tia Neiva, no Distrito Federal. Afinal, todos os itens apontados nas duas colunas da Tabela 1 ficam à mercê não apenas de nossa observação externa, mas também de nossos próprios conteúdos valorativos. Para ilus- trar, tomemos como foco de reflexão o aspecto apontado na última coluna da tabela e nos perguntemos se o que se considera como tendo funções "integradoras" na vida não sofreria variações de julgamentos conforme se adote um ou outro sistema de valor. Assim, se nos voltamos, por exemplo, para a análise do ocorrido com Jacobina Mentz ${ }^{1}$, constatamos que a experiência religiosa foi vivida por ela própria, bem como pelos integrantes da comunidade por ela fundada, como sendo de natureza profundamente integradora. Entretanto, tal experiência foi interpretada, desde o início, pelos líderes religiosos e, posteriormente, também por médicos e políticos da localidade, como extremamente perigosa, ameaçadora e desintegradora. Tanto que, baseados neste argumento, chegaram a levar ao violento extermínio da referida líder religiosa e seus adeptos, estes últimos estigmatizados pela comunidade local com a denominação pejorativa "os Muckers".

Uma perspectiva fenomenológica vai exigir revisão bastante crítica do paradigma supostamente objetivo que deu origens aos critérios de forma e conteúdo elencados na referida tabela, e que foram ditados por uma ciência que se pretendeu absolutamente confiável ao defender distinção asséptica entre um saber técnico e outro especificamente humano. A mudança paradigmática possibilitada pelo olhar fenomenológico, ao invés de procurar afastar o vivido a favor de uma elaboração assepticamente técnica, busca incluí-lo, reconhecê-lo e valorizá-lo por si mesmo, tomando-o como fundamentalmente intrincado às questões humanas que deram origem ao conhecimento e aos quais estes se reportam. Esta postura é fundamentada no aporte filosófico desenvolvido por Husserl (1950/2000) e, posteriormente, reelaborado por Merleau-Ponty (1945/1999).

Especificamente em relação ao tema da religião, alguns textos de Husserl mostram uma reflexão filosófica tanto de cunho teórico quanto ético sobre o problema de Deus, como o apontam as investigações de Bello (1998; 2000). Embora sua posição a respeito das relações entre filosofia e religião tenha sido muito clara, propondo que a primeira comporte-se como a-téia, enquanto via de pesquisa, o filósofo apresenta várias indicações acerca do Absoluto (quoad se) e da consciência enquanto ponto de partida (quoad nos). Conforme interpreta Bello (1993/2000), tais indicações giraram sempre em torno da questão do "sentido", de modo que a análise fenomenológica, enquanto descrição, não vai se deter propriamente no dado tomado em sua facticidade, mas sim na possibilidade de se conhecer, intuitiva e imediatamente, o sentido desse dado, tomando-o como uma questão fundamental.

A originalidade husserliana se deu por denunciar o grande mal-estar decorrente da polarização entre uma perspectiva idealista e outra empirista, e caracterizando-se

\footnotetext{
1 Jacobina Mentz: líder religiosa que esteve à frente da Revolta dos Muckers, ocorrida no Rio Grande do Sul na segunda metade do século XIX. Vide filme denominado "A Paixão de Jacobina", dirigido por Fábio Barreto e baseado no romance "Videiras de Cristal", de Luiz Antônio de Assis Brasil, o qual relata a história da mesma.
} 
por priorizar os modos de racionalidade intuitiva, os quais não correspondem às estruturas estritamente de cunho lógico-formal (1936/2008). Por não serem completamente irredutíveis a rotinas governadas por algoritmos (Freitas, 2012), este modo de racionalidade dá lugar a um conhecimento sensível, ou seja, que se dá a partir da própria experiência ao invés de se situar apenas além ou fora dela. Neste sentido, o pai da fenomenologia possibilita uma crítica consistente à redução da ideia de mundo, convidando à abertura de um campo fenomenal que nos propõe reencontrar a experiência direta em relação ao outro, não devendo esta ser meramente categorizada enquanto suposto saber cientifico, psicológico ou filosófico. Em outras palavras, se queremos que a reflexão conserve os caracteres descritivos do objeto ao qual ela se dirige e o compreenda verdadeiramente, não devemos considerá-la como o simples retorno a uma razão universal, mas realizá-la antecipadamente no irrefletido, considerando-a como uma operação criadora e participante, ela mesma, da facticidade do irrefletido, em sua intencionalidade própria e constitutiva. Se aplicarmos isso à consciência e experiência religiosa, isso não quer dizer que, para Husserl, o misticismo seja uma experiência da ordem do puramente "irrefletido", mas dele emerge também como uma "possibilidade ideal" que convoca a imaginação, como todas as demais experiências humanas em seu potencial.

Em continuidade, também o fenomenólogo Merleau-Ponty (1945/1999) aponta, criticamente, que a reflexão nunca tem sob seu olhar o mundo inteiro e a pluralidade das mônadas desdobradas e objetivadas; ela em geral dispõe de uma visão parcial e de uma potência limitada. Compreendemos a noção de mônada, a partir de Leibniz (1714/1979), que nos diz que a mônada demonstra aquilo que o ser é, em sua unicidade e seu lugar no cosmos, tendo em vista a identidade e a diferença dos pontos substanciais que compõem o mundo. Assim, vemos que a mônada não se resume a um modo empírico, mas vai para além da pura condição apresentada pelas limitações da matéria e da percepção. Pensamos, tal como o filósofo, que a mônada significa um modelo exemplar que dá vazão a um ato descritivo do universo, mostrando originariamente a incapacidade de apreendê-lo.

A partir desta perspectiva, temos que considerar que, quando o juízo passa a ser visto como um julgamento, modelo da psicopatologia tradicional, podemos ter prejuízos no ato de perceber um objeto. É isso o que mostra Merleau-Ponty (1945/1999), ao fazer uma crítica à percepção empírica. Ou seja, ao definirmos um delírio religioso como juízo falso da realidade, ou como alteração do pensamento, podemos estar reduzindo a realidade a um discurso tecnicista que geralmente não contempla as muitas realidades que podem estar encobertas por trás de uma realidade que aparece. Esta percepção das mônadas umas sobre as outras é que leva a uma postura de abertura diante do objeto de estudo, receptível ao como ele quer se mostrar, de forma que passamos a tratá-lo co- mo uma pedra bruta prestes a ser lapidada. E, percebam, uma pedra que interage com aquilo e aquele que a lapida.

Por analogia, tomemos o exemplo das retas de Müller-Lyer, reproduzidas de Merleu-Ponty (1945/1999, p. 27), na Figura 2. Embora não se pretenda aqui reduzir fenomenologia da religião à fenomenologia da percepção, esta figura é muito interessante para ilustrar as diversas maneiras pela qual um/a psicólogo/a clínico/a pode lidar com a estranheza e/ou a ambiguidade de uma determinada experiência religiosa, dada a percepção daquilo que lhe é muitas vezes apresentada pelo paciente, no seu esforço de estabelecer suas conexões e distinções das experiências psicopatológicas.

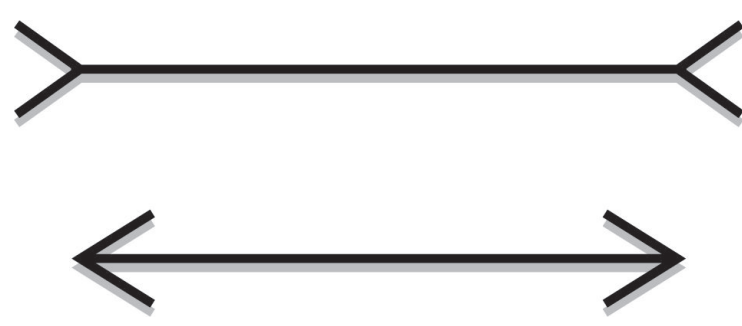

Figura 2. Retas de Müller-Lyer

Assim, por exemplo, o/a psicólogo/a pode adotar postura equivalente à do observador que, diante destas duas retas, age peremptoriamente movido pelo intuito de identificar se elas são iguais ou desiguais. Este observador, preocupado em chegar a uma conclusão que lhe seja absolutamente fiável do ponto de vista científico, desconfiará, logo de saída, daquela primeira impressão inicial de que estas retas são desiguais. Tal desconfiança substitui, no plano reflexivo, aquela primeira impressão visceral que ele/a agora a chamará de ingênua e/ou precipitada - e será acompanhada da busca de recursos para medir objetivamente o tamanho das retras centrais. Ao medi-las e constatar que as linhas centrais são do mesmo tamanho, descarta por completo aquela primeira impressão visceral que lhe fazia acreditar, no plano perceptivo inicial, de que elas são desiguais.

Ora, se diante de uma manifestação religiosa trazida no contexto clínico, o/a psicólogo/a agir como o nosso observador imaginário, ele/a deixará de qualificar justamente aquelas impressões primeiras, da ordem da sensibilidade, com as quais se viu afetado/a de primeira mão diante da experiência do outro, e passará de imediato à uma comparação fundamentada tecnicamente entre aquilo que é, de fato, uma experiência religiosa e aquilo que caracteriza um delírio religioso, partindo do princípio que esta dimensão supostamente objetiva é que lhe traria resposta fiável, científica. Ocorre que aquele "descarte" das impressões iniciais efetuado pelo nosso observador imaginário se deu à custa de certo "mascaramento"; um esforço consciente de negação das impressões pré-predicativas, irrefletidas, pois que esta impressão original de que as retas são desiguais nunca se desfaz por completo. Afinal, por mais que cada um de nós tenhamos nos deparado inúmeras vezes 
com as retas de Müller-Lyer, identificaremos sempre, em nós mesmos, a impressão visceral de que elas são desiguais. Metaforicamente, o psicólogo/a estará cometendo este mesmo equívoco.

Mas, digamos que nosso observador imaginário fizesse o contrário: ficasse apenas com aquela impressão primeira, sem nenhum comprometimento com a atividade reflexiva que lhe daria acesso àquela verdade secundária, de cunho científico, tomando justamente a impressão visceral inicial como verdade, ou seja, concluindo que as retas são de fato desiguais. Um/a psicólogo/a clínico que agisse de maneira equivalente não só qualificaria a experiência religiosa que lhe fora trazida pelo seu paciente, ou usuário do serviços em que atua, como também assumiria como verdade absoluta o impacto original que lhe fora impresso diante dela. Do ponto de vista ético, isto teria diversas implicações, caracterizando facilmente uma perspectiva religiosa em substituição a uma perspetiva profissional. Por isso, esta perspectiva precisa ser acompanhada de um movimento reflexivo, de cunho ético e epistemológico, sob pena de desresponsabilizar o psicólogo do seu lugar de profissional.

As duas posições ilustradas anteriormente retratam duas alternativas possíveis diante da condição de um observador que se impôs previamente a necessidade de decidir por uma resposta ou outra: ou estas retas são iguais ou elas são desiguais. De modo equivalente, no caso do psicólogo/a, a imposição de uma decisão fechada seria, por exemplo: ou esta experiência é legitimamente religiosa ou se trata de delírio religioso. Ou seja, o problema central está naquela exigência categorial de saída perante uma experiência que é do outro mas que é também compartihada, tornando o vivido objeto de mera escrutinização técnica. E é justamente com tal exigência que a fenomenologia evita compactuar de saída. Em outras palavras, para o fenomenólogo, esta exigência não se impõe.

Ao trazer o exemplo das retas para ilustrar a dicotomia entre o empirismo e o idealismo, Merleau-Ponty (1945/1999), por muitos designado como o filósofo da ambiguidade, nos faz um convite à atitude contemplativa. Ou seja, a de que nos debrucemos mais longamente sobre o fenômeno que se nos apresenta, atentando-nos simultaneamente e ainda mais profundamente sobre aquele complexo de atos e operações que constituem a nossa consciência e o modo como ela se vê afetada diante, pela e na presença do que se lhe é mostrado. Desta forma, um observador que adota esta terceira postura, ao visualizar a Figura 2, poderia descobrir, por exemplo, que as duas retas abertas nas extremidades na reta superior, quando integradas ao movimento intencional operante de sua consciência, expressaria de modo intuitivo impressão de abertura e extensão, enquanto que o contrário ocorreria com as duas retas fechadas nas extremidades da reta inferior, imprimindo-lhe impressão de fechamento e contração. Vê-se aí, então, movimento simultaneamente intuitivo e reflexivo, que lhe permitiria compreensão ge- nuinamente fenomenológica, concluindo, p.e., que sua primeira visada, em ato, é acompanhada de uma espécie de apreciação intuitiva, onde a primeira reta superior é percebida como maior em potencial, enquanto a inferior, menor em potencial.

Ora, a atitude acima descrita implicaria assumir que "a unidade da experiência não é garantida por um pensador universal que exporia diante de mim os conteúdos da experiência e me asseguraria, em relação a eles, toda a ciência e toda a potência” (Merleau-Ponty, 1945/1999, p. 394). Em vez disso, ela deveria ser sempre buscada em seu estado nascente, ainda que reconhecendo-a sempre envolta nos limites do horizonte perceptivo, mostrando-se e escondendo-se simultaneamente, no seu contínuo e sempre incompleto desvelar-se. Isso exigiria do psicólogo, no exame da experiência religiosa e de suas respectivas conexões ou distinções do delírio místico, despojar-se de quaisquer preconceitos ou valores a priori, inclusive daqueles que se sustentam sobre certezas supostamente científicas ou dadas por sucessivas constatações empíricas, como se lhe quiseram fazer crer serem as diversas classificações dos manuais psiquiátricos. Tal esforço, de "redução fenomenológica”, nunca será tarefa acabada, pois ela depende de uma intencionalidade temática no seu movimento sempre incompleto de alcançar a intencionalidade operante. Entretanto, é por meio dele que se pode assegurar uma perspectiva realmente crítica e não meramente reprodutora dos jargões disponibilizados pela linguagem psiquiátrica ou psicologizante.

Curiosamente, um famoso líder messiânico no Brasil demandava esta mesma espécie de despojamento, talvez justamente por ter experimentado, em si mesmo, as vicissitudes e riscos de um diagnosticado psiquiátrico, objetivante. Deste modo, assim alertava acerca da inadequação de um olhar escrutinizador e meramente classificatório sobre as experiências religiosas: "Procurar entender um fenômeno, antes de entregar-se à sua sensação interior, à repercussão dele no ponto central místico de todos nós, é o mesmo que querer descobrir a vida estripando cadáveres" (Yokaanam, versão 2011, p. 21). Naturalmente que o compromisso e a responsabilidade profissional do/a psicólogo/a exigem que ele/a não fique apenas nesta primeira perspectiva, intuitiva, sendo necessário que busque avançar rumo à reflexividade da experiência em foco, fazendo valer o verdadeiro sentido do verbo "entender".

O filósofo Merleau-Ponty não se enveredou mais propriamente para o terreno específico da psicopatologia. Mas, no decorrer da história deste campo de confluência entre psicologia e psiquiatra, muitos outros autores o haviam feito, dentre eles o filósofo, médico e fenomenólogo alemão Karl Jaspers (1913/1979), cuja obra "Psicopatologia Geral: Psicologia compreensiva, explicativa e fenomenológica” tornou-se bem conhecida no Brasil. Vemos, na proposta jaspersiana, um esforço de realizar, concretamente, aquela terceira posição descrita anteriormente, como buscaremos ilustrar no subitem a seguir. 


\section{Conciliando as posturas humana e profissional}

Ao buscar oferecer instrumentos para que se possa diagnosticar um delírio, diferenciando-os, por exemplo, de uma experiência espiritual religiosa, Jaspers (1913/1979) reconhece que também o delírio é um grande enigma, só sendo possível de ser interpretado quando se conhece com precisão os fatos que o acompanham e lhe constituem. Questiona, então: se chamamos delírio qualquer juízo falso, incorrigível, essa realidade humana universal, quem haverá que não delire, desde que, afinal, seja capaz de uma convicção? Neste sentido, conclui que, quem pensa serem ideias delirantes as ilusões fecundas que se vêm na vida dos povos e na existência do indivíduo, acaba por tratar como doença algo que é traço básico no ser humano. A questão está muito mais em saber no que se funda a incorrigibilidade da crença defendida pela pessoa, devendo, portanto, tanto o delírio como a experiência religiosa, serem compreendidos em seu rendimento psicológico, em sua fenomenologia, em sua compreensão genética e no entendimento global de seu significado factual.

Naturalmente que, ao tentarmos nos aproximar das vivências delirantes primárias, ou de experiências religiosas que nos soam completamente singulares, logo notamos que não nos é possível apresentar de maneira concreta os modos de vivência estranhos para nós. Sobra sempre um resto de algo (in)compreensível, (in)apreensível e (im)perceptível. Deste modo, toda compreensão de processos reais particulares subsiste, mais ou menos, como interpretação, e só em casos raros se consegue alcançar graus de perfeição do material objetivo convincente. Se compreendemos, diz Jaspers (1913/1979), é na medida em que os dados objetivos dos movimentos expressivos, atos, manifestações verbais, auto narrações, impõem, mais ou menos, semelhante compreensão.

O autor diz também que, liberta de qualquer realidade concreta, é evidente uma conexão psíquica, mas só podemos afirmá-la na medida em que nos são fornecidos os dados objetivos. Chama, portanto, nossa atenção para estes dados objetivos, ressaltando entretanto que, quanto mais os interpretamos, menos os compreendemos. Nesta perspectiva compreensiva, tem o cuidado de destacar o caráter inefável da experiência vivida, já que esta conserva sempre um fundo remanescente inexaurível. Assim, reconhece que interpretar é necessário, chegando inclusive a propor alguns modos explicativos para definir o delírio, as quais coincidem com alguns daqueles contemplados anteriormente no Tabela 1, buscando trazer elementos para constituição de um saber técnico ao qual o profissional de saúde mental não pode se esquivar. Entretanto, o fenomenólogo chama a atenção para que esta postura jamais se aliene de uma percepção contextualizada, empática, compreensiva e intuitiva, devendo aceitar seus limites em se tratando da complexidade da experiência humana.

Metaforicamente, poderíamos aqui propor, então: que a nossa conclusão lógico-perceptiva quanto à igualda- de das retas centrais, mostradas na Figura 2, jamais nos aliene daquela impressão primeira de que elas são desiguais. Ao fazermos isso, estaríamos jogando fora a água suja com o bebê junto e nos alienando daquela dimensão visceral, sensitiva e intuitiva que também nos constitui enquanto seres humanos habitando um mundo que se nos apresenta sempre como fenômeno, e nunca, jamais como puro fato objetivo.

A concepção jaspersiana de se ater aos elementos que designa de "rendimento psicológico" pode bem ser aproximada da proposição do pensar pragmático de William James (1902/1995), no sentido de que toda experiência, independente de ser previamente classificada como delirante ou genuinamente religiosa, deva ser compreendida a partir do mundo da vida da própria pessoa, ou seja, o que ela significa e o impacto disso na vida pessoal e relacional, em que é dada atenção ao indivíduo e às suas variadas formas de comportamento. Enquanto Jaspers cuidou de descrever os delírios, W. James cuidou de descrever os fenômenos religiosos, considerando-os como estados mentais concretos, sendo que as emoções que os acompanham são entidades psicológicas distinguíveis de outras emoções, estando em regiões diferenciadas da consciência, com as seguintes características: inefabilidade, dimensão noética, transitoriedade e caráter de passividade. Neste sentido, aproxima-se também de Wittgenstein (1921/1968), ao dizer que a inefabilidade, para quem a experimenta, desafia a expressão, pois não se pode fazer com palavras nenhum relato adequado do seu conteúdo. Disso se segue que a sua qualidade precisa ser experimentada diretamente; não pode ser comunicada nem transferida a outros.

A qualidade noética, para James (1902/1995), diz respeito aos estados de conhecimento para quem tem experiências místicas. São iluminações, revelações cheias de significado e importância. Via de regra, carregam consigo um senso curioso de autoridade pelo tempo sucessivo. A transitoriedade refere-se aos estados místicos que não podem ser sustentados por muito tempo. A não ser em casos raros, meia hora, ou, quando muito, uma ou duas horas, parecem ser o limite além do qual eles se desfazem gradualmente à luz do dia.

Por último, a passividade. Segundo James (1902/1995), depois que a espécie característica de consciência se impõe, o místico tem a impressão de que a sua própria vontade está adormecida e, às vezes, de que ele está sendo agarrado e segurado por uma força superior. Esta última particularidade liga os estados místicos a certos fenômenos definidos de personalidade secundários ou alternativos, tais como o discurso profético, a escrita automática ou o transe mediúnico. Entretanto, segundo o autor, quando estas últimas condições são bem pronunciadas, pode não haver nenhuma recordação do fenômeno, e pode não haver significação alguma para a vida interior usual do sujeito, para a qual, por assim dizer, ele representa uma simples interrupção. 
James (1902/1995) nos alerta que a divergência mostra o quanto é importante não desprezar nenhuma parte das conexões de um fenômeno, pois nós o fazemos parecer admirável ou medonho de acordo com o contexto no qual o estudamos. $\mathrm{O}$ autor ressalta que o conhecimento de Deus, Sagrado, Divino ou Transcendente, ou seja, daquilo que se constitui o objeto/sujeito da crença religiosa, não pode ser apenas discursivo; tem de ser intuitivo, isto é, tem de ser construído mais segundo o padrão do que, em nós mesmos, se chama sensação imediata, do que segundo a proposição do julgamento.

A perspectiva descrita acima é condizente com o que tratamos no início deste capítulo acerca da noção de experiência. Ao se referir à experiência religiosa, Edênio Valle (1998) considera que qualquer experiência, fato, fenômeno ou objeto pode ser hierofânico, isto é, revelador do divino, para os seres humanos em busca de transcendência, seja qual for essa. Mas ao mesmo tempo, o mistério inefável, presente no fenômeno, essa última e sempre oculta dimensão da fé religiosa, jamais é atingido, não pode ser explicado, apenas tangenciado. Assim é que o autor nos diz que a experiência religiosa é atingida, de modo muito especial, por essa ambiguidade radical, constituindo-se como uma noção equívoca.

Retornando, então, à postura compreensiva proposta por Jaspers (1913/1979), consideramos que ela demarcou um avanço da ciência psicológica no sentido de acolher o outro sem os pressupostos, pré-juízos, pré-conceitos, tão caros à psicologia, para alcançar o outro de modo empático, sensível, intuitivo e que vá de encontro ao que se mostra à nossa consciência. Este nível do pensamento e práxis acaba sendo colocado em dúvida quando escapa da padronização explicativa e interpretativa, que permitiu à psicologia ascender-se como ciência. Neste sentido, vemos a necessidade de retorno à epistemologia desta ciência, examinando cuidadosamente o que foi deixado para trás e que mudou os rumos de sua práxis.

Revendo o legado de Jaspers, percebemos que suas perspectivas vão além do modelo meramente explicativo, o qual foi adotado e ainda tende a vigorar, de forma hegemônica, no ocidente. Sob o aspecto da existência, Jaspers (1913/1979) diz que o (in)compreensível é a liberdade que se apresenta na decisão incondicionada, na apreensão do sentido absoluto; como se apresenta na experiência básica, quando, a partir da situação empírica, se forma a situação marginal que desperta a existência para a autonomia. Vemos, através de sua psicologia compreensiva, que a iluminação existencial toca esse mais do que compreensível, toca a própria realidade na possibilidade da autonomia, recordando, alertando e revelando.

Assim, Jaspers (1913/1979) pensa que o ser humano não é simples realidade empírica; mas, sim, como tudo mais quanto é real, ele se vem a fazer significativo, embora sem possibilidade de verificação, numa contemplação metafísica. $\mathrm{O}$ autor ainda diz que à ciência psicopatológica cabe esclarecer os fatos que iluminam a experiência metafísica. Sendo assim, consideramos que iluminar a experiência religiosa implica em reconhecermos o aspecto metafísico contido na sua experiência empírica. Ou seja, há atitudes, pensamentos, modos de funcionamento que se mostram como que (in)exprimíveis, (in)cognoscíveis, (in)explicáveis do ponto de vista da ciência positivista, mas isto não implica dizermos que estes não fazem parte da experiência. Há que se considerar que o imanente e o transcendente fazem parte da experiência humana e se fazem presentes na sensibilidade, na intuição e na intencionalidade da consciência daquele que está em contato com experiências humanas.

Neste sentido, o autor ressalta que não é possível compreensão psicológica sem que se pense em conteúdos (imagens, formas, símbolos, ideias); sem que se veja expressão, sem que se co-vivenciem os fenômenos vivenciados. Do mesmo modo, não se pode falar nos conteúdos sem se pensar na realidade psicológica para a qual existem; não se pode contemplar a expressão sem compreendê-la em seus motivos; e quase não se pode descrever coisa alguma sem ver, de imediato, as conexões compreensíveis. Ou seja, o procedimento do psicólogo compreensivo significa partir de uma intuição compreensiva total, pela qual se tomam as formas expressivas e os fenômenos apresentados em seu conjunto, em termos de forma e conteúdo, que podem também ser decompostos e esclarecidos de uma perspectiva explicativa e analítica por mecanismos lógicos ou extra conscientes, percebendo-se a possibilidade da existência como base suscetível de investigação empírica, mas considerando-se que esta última se esbarrará constantemente nos seus próprios limites.

\section{Ilustrando com o caso Yokaanam}

A história messiânica do Mestre Yokaanam pode ser considerada um caso paradigmático do que viemos expondo até aqui. Ela foi descrita e refletida do ponto de vista fenomenológico em outros estudos desenvolvidos por estas autoras (Vilela, 2015; Vilela \& Freitas, 2016), tomando-se seus próprios manuscritos como principal fonte de análise, combinando-se, portanto, análise documental e descrição da história de vida. Por outro lado, a trajetória do referido líder tem chamado a atenção de antropólogos, sociólogos, historiadores (Negrão, 2001; Mello, 2004; Cipriano, 2005) e de importantes psicopatologistas, como foi o caso do cubano Emílio Mira y Lopez (1957), criador do teste miocinético PMK. Este último chegou a ilustrar, em um de seus livros, a experiência do referido líder messiânico como um caso de "paranoia religiosa", sendo que tal diagnóstico teve caráter polêmico e controverso. Elegemo-la, portanto, para ilustrar resumidamente as implicações clínicas do que expomos anteriormente.

Um olhar fenomenologicamente crítico permite considerar, inicialmente, que a experiência deste líder messiânico se deu num campo não apenas subjetivo, ou do 
que ele próprio descreveu como da ordem de um dom profético-mediúnico e que lhe fora revelado pela divindade espiritual. Ela se estendeu também para um campo intersubjetivo, ao ser legitimada pelo seu contexto e pelo imaginário social, num momento histórico do país em que o próprio carisma do Mestre foi também nutrido pelas necessidades, anseios e fé daquelas pessoas que decidiram segui-lo.

Conforme aponta Cerqueira (2014), os movimentos messiânicos não nascem por decreto, ou por voluntariedade de um indivíduo iluminado. Estes movimentos só acontecem quando pessoas estão incomodadas e começam a canalizar seu mal-estar na busca de alternativas de solução. Há que se considerar, portanto, que o movimento messiânico do Mestre Yokaanam foi impulsionado pelo processo de interiorização do país e inserido na perspectiva de uma Brasília erguida sob o ímpeto do sagrado, como nos mostra Araújo (2009). A autora chama a atenção para a pressão social, econômica e religiosa que os migrantes ecléticos fraternários enfrentavam no contexto da criação da Fraternidade Eclética. Destaca ainda o imaginário social em que a capital de Brasília foi construída, num ideário de paraíso de fartura e abundância, que resultaria em uma civilidade ideal, numa perspectiva de desenvolvimento e integração nacional com uma ideia visionária da terra prometida.

Deste modo, Brasília e seu entorno apresentou, desde suas origens, como campo de experiência e de produção que reúne vários elementos representativos desse novo tempo, mas que se ligam a outras fontes, além do mito místico que envolve a sua construção. Emerge no espaço da capital a experimentação, o convívio, a integração de várias sistematizações religiosas oriundas de diversas doutrinas e de outras visões de mundos. Segundo Araújo (2009), estas representações simbólicas e sagradas marcam tanto o imaginário social de Brasília, quando propiciam o surgimento de seitas e grupos responsáveis por uma nova visão de mundo. Sensível a este aspecto, mestre Yokaanam instaura sua cidade santa nos arredores da mística Brasília e consolida assim o ideário da terra prometida.

Se retomamos aqui a metáfora das retas de Müller-Lyer, poderíamos dizer então que os seguidores de Yokaanam se mantiveram na primeira impressão visceral, pré-reflexiva, pois esta lhes fazia total sentido diante de suas perspectivas naquele momento. Enquanto isso, ao expor o diagnóstico de paranoia religiosa, o médico cubano desprezou esta primeira impressão, e se manteve naquela impressão secundária, reflexiva, fruto de uma perspectiva meramente analítica e classificatória, e que, ao invés de primar pela sua avaliação pragmática, primou pela sua avaliação técnico-científica e categorial.

Inspirados na postura fenomenológica descrita anteriormente, como poderia então se posicionar o/a nosso/a observador/a ou psicólogo/a imaginário/a diante deste caso, adotando aquela posição que não se compromete de saída em decidir se aquelas retas são iguais ou desiguais?
Qual seria a resposta clínica deste psicólogo/a compreensivo diante da experiência deste que nos relata, em sua própria autobiografia, que seu movimento teve início na década de 40, quando ele mobilizou e converteu centenas de famílias para sua religião, a Fraternidade Eclética Espiritualista Universal? Esta comunidade foi depois fundada oficialmente no Estado do Goiás, mas remanescente da sua origem no Rio de Janeiro. Yokaanam passou a realizar curas espirituais e se experimentava como um profeta. Mudou então suas vestimentas e sua aparência. Com cabelos e barbas longas, vestido com seu balandrau, pregava a união das religiões, dava assistência a crianças carentes e acolhia os que estavam dispostos a seguir seus mandamentos inspirados nas doutrinas cristã, espírita e umbandista. Buscou aproximar-se também da maçonaria, do budismo e das filosofias que falam do cosmos universal.

O trabalho de Yokaanam (Versão 2011), conforme ele próprio descreve, foi realizado no meio da pobreza, e muitos homens não sabem quem é ele, demonstrando curiosidade com sua figura estranha e supondo que ele seja um homem especial ou esquizofrênico. À sua maneira, ele busca tranquilizar seus fiéis citando o exemplo de Jesus, e diz para que não se escandalizem por chamarem-no de doido e quererem colocá-lo em um manicômio. Alega que aqueles cientistas que tiveram estas intenções sabem que ele é uma "parada dura nesta jornada dos dias que precedem ao fim dos tempos", sabem que ele é o "delegado previsto para restaurar, antes, todas as coisas" e, por isto, quiseram interná-lo.

Como compreender o relato daquele que se intitula Mestre e que começou a desenvolver suas atividades mediúnicas aos treze anos de idade? Como diagnosticar a sua conviç̧ão de que foi do milagre de ter sobrevivido a um acidente provocado pela queda do avião que pilotava, que emergiu então sua decisão por "seguir seu chamado messiânico", ou seja, exercer sua mediunidade, realizar as curas espirituais e ajudar ao próximo? Como responder empaticamente a uma experiência sobre a qual identificamos, de saída, a (im)possibilidade de termos acesso completo ao seu mundo, através do mundo sensível? Fenomenologicamente, uma primeira atitude será assumir que, embora este seu mundo possa nos ser (in)acessível, isso não implica que seja inexistente, já que podemos constatá-lo pelo seu comportamento e modo de reagir, assimilada em seu contexto como a de um benfeitor, a ele e ao próximo; neste sentido, distanciando-se daquilo que a própria ciência estabelece como doença mental, pois que esta é associada a sofrimento e à incapacitação para a vida.

Se pensamos na ótica daquilo que clinicamente se conhece por paranoia, sim, vemos em Yokaanam um delírio persecutório, quando afirma que todos tramam contra ele, quando ele se sente um enviado de Deus, um ser especial. Ele se disse profeta, e isto requer um psiquismo inflacionado, que se evidencia nas suas auto-intitulações e suas relações com os grandes mestres espirituais da hu- 
manidade. Mesmo assim, não se tem nenhum instrumento objetivo para se afirmar que isto seja ou não verdade. De todo modo, a práxis fenomenológica considerará a descrição da percepção de Yokaanam sobre sua experiência, numa postura compreensiva e não meramente interpretativa. Além disto, não fechará os olhos para seu compromisso de altruísmo junto à sua comunidade, o que não parece constituir muito o quadro psicótico, tradicionalmente caracterizado com sintomas de ensimesmamento e alienação da realidade externa. Como aponta estudo etnográfico realizado por Mello (2004, p. 38), no âmbito da Cidade Eclética, para os discípulos de Yokaanam, ele é tido como símbolo da esperança de que a humanidade siga o exemplo de altruísmo, desprendimento material e atitude de humildade. Reconhecer estes sentidos, que se situam no fundo do coração destes seus seguidores, não é o mesmo que assumir que o bem que ele tenha praticado o redima de qualquer patologia. Não se trata disso! Isso implica abrir-se à experiência subjetiva e intersubjetiva de outrem, que mesmo que se apresente por meio de um eu inflacionado, mostra-se também, efetivamente, como aquele que ama e que é amado.

Diante desta constatação, cabe então ao profissional da saúde mental rever o que aprendeu sobre psicopatologias, seus funcionamentos, seus contextos, já que um diagnóstico psiquiátrico implica, de antemão, aproximar-se de uma experiência humana com um certo viés, um olhar que pode ser estigmatizante e mudar o destino da pessoa. Esta opção, de colocar entre parêntesis todas formas de $a$ priori caracterizadas pelos saberes indexadores, permite-lhe qualificar a experiência vivida pelo outro, presente na esfera de sua consciência, e que ele busca compartilhar conosco. No caso de Yokaanam, sua experiência é a de um homem que considerava ter um destino religioso e espiritual traçado já desde que nasceu, quando foi curado e sua própria mãe teve uma visão de que ele seria especial. Na sua vivência subjetiva e intersubjetiva, isso lhe fora confirmando ao longo de sua vida por diversas vezes, inclusive mais tarde quando foi chamado por Como deve ficar: um general que lhe comunicou que, a partir de então, seu caminho seriadiferente do de um piloto de avião.

Bello (1998) nos alerta de que o papel da fenomenologia é descobrir os momentos essenciais e característicos das várias ontologias regionais, ou seja, dos diversos domínios do saber, onde o termo ontologia adquire um significado totalmente diferente do tradicional de investigação em torno do ser, apontando não a questão da essência, mas investigando o que é a realidade de um determinado domínio do saber. Pensando assim, o clínico também se volta para a realidade de Yokaanam a partir do que ele mesmo busca mostrar.

Do ponto de vista explicativo e interpretativo, o clínico poderia diagnosticar Yokaanam como um homem que, após a queda de um avião que pilotava, teve um surto psicótico, desenvolvendo um modo de funcionamento paranóico. Este tipo de interpretação se fundamentaria inclusive na própria psicopatologia explicativa Jasperiana, quando esta prioriza a forma e o conteúdo do delírio. Assim, temos um homem profano se transformando em profeta, com muitas auto-referências e auto-intitulações, com mudanças de hábitos e aparência, com "poderes espirituais de cura”, ensimesmado, projetivo, com pensamentos persecutórios em torno daqueles que não o reconheceram como um ser especial. Poderíamos desenvolver um estudo nesta perspectiva e teríamos em seus escritos fundamentos para tais explicações. Mas, este mesmo clínico, se minimamente imbuído de sensibilidade, questionaria a epistemologia deste modo de fazer ciência, a ética em se adotar tal postura, as consequências dela na práxis clínica da saúde mental de pessoas que, como Yokaanam, apresentam discursos e manifestações de ordem religiosa e/ou espiritual.

Atendo-se a uma postura compreensiva e não meramente interpretativa, a percepção deste clínico acerca de Yokaanam buscaria compreender o que a sua experiência significou para ele, considerando-se aí os efeitos de tal significância. Veria aí, então, também um homem que deixou um legado para a humanidade, fundou sua doutrina, prestou assistência aos doentes e necessitados e compreendeu isso como uma forma de realizar sua “missão". Embora isso não venha, por si só, a redimi-lo de qualquer suposta palotologia mental, associar estes fatos a uma doença psíquica acaba sendo incompatível do ponto de vista social, já que a "doença” é algo que se presta muito mais a destruir que propriamente construir destinos bem-sucedidos, como este de Yokaanam. Assim é que, ao pensarmos na sua experiência religiosa e, ampliando nossos horizontes, na experiência humana de todos aqueles que nos chegam, temos como premissa este exercício de se considerar estes modos de existir no mundo. Esta postura pode ter implicações decisivas no modo de se compreender, diagnosticar, lidar e tratar os mais diversos fenômenos no campo da saúde mental.

No âmbito da Psicologia da Religião, temos o legado de Vergote (1969), que também nos inspira a recorrer às crenças que sejam observáveis ao nível das expressões verbais, simbólicas e comportamentais, buscando investigar, enquanto clínicos, a maneira especifica de se colocar, daquele que nos diz vivenciar uma experiência religiosa, em relação com aquilo que ele crê ser "absoluto". Ao fazer isso, embora exercendo o princípio da "exclusão metodológica do transcendente", princípio enunciado por Flournoy, o/a psicólogo/a jamais tomará o "absoluto", ou Deus, como seu objeto de observação, mas sim os atos propriamente humanos dirigidos a Ele, sem deslegitima-los.

Ou seja, ao se deparar com a experiência religiosa do outro, o/a psicólogo/a não pode simplesmente fazer coincidir a vida religiosa com a vida psicológica, devendo manter o caráter referencial da intenção da consciência e do ato religioso. Deste modo, o estudo e a compreensão do psiquismo deve respeitar a especificidade da consciência humana, que é uma consciência aberta ao mundo, 
aos outros, a Deus, e que reduzir a religião ao puramente humano, em si mesmo, equivale a desnaturalizar o objeto da psicologia religiosa.

Edênio Valle (1998) complementa esta ideia ao dizer que a tarefa da psicologia da religião, no âmbito das ciências humanas, é estudar a origem e a natureza da mente religiosa humana. Neste sentido, ela não busca definir o que a conduta religiosa é, e sim porque e como alguns fenômenos religiosos se dão no interno da estrutura psicológica de um sujeito. Este último autor faz uma interessante analogia ao falar do campo da psicologia. Ele diz que, até o século XIX, a psicologia era apenas uma província do imenso império da filosofia e/ou da teologia. Foi conquistando, aos poucos, sua autonomia, mas guarda ainda uma íntima conexão com a discussão conceitual filosófica que lhe é subjacente.

Retornando a Vergote (1978/1998), importante lembrar também que, embora a religião tenha se convertido em objeto de interpretação para a nova ciência psicopatológica, esta jamais encontrou explicação científica para concepções religiosas ou espiritualistas ou evidências que pudessem confirma-las ou refutá-las. Também Aletti (2012) ressalta que o que qualifica ou é qualificado pelos métodos e os modelos da psicologia, ao buscar estudar e compreender o fenômeno religioso e/ou espiritual, não é a religião em si, mas a pessoa religiosa. Desconsiderar isso é cometer grave equívoco ético e epistemológico.

Carrette $(2004 ; 2013)$ considera que não há como escapar ao método de James, ou seja, de análise da experiência humana segundo a simples coleta de experiências a partir de relatos pessoais. Assim também qualifica o relato narrativo da experiência, retirando do cientista a autoridade da interpretação dessa experiência e apontando para a necessidade de uma auto-reflexividade em relação aos processos cruciais que caracterizam a hermenêutica e a política de nossa representação da mesma.

O código de ética do psicólogo (Conselho Federal de Psicologia, 2005) é frequentemente citado por estudantes e psicólogos quando entrevistados sobre o modo como lidam com a religiosidade de seus pacientes (Freitas, 2012; 2013; 2015). Conforme Neubern (2013), a tendência é se concentrar, de modo quase obsessivo, no art. 2, item b, o qual diz que "ao psicólogo é vedado induzir convicções políticas, filosóficas, morais, ideológicas, religiosas, de orientação sexual ou a qualquer tipo de preconceito, quando do exercício de suas funções profissionais".

Entretanto, o/a estudante ou profissional esquece-se de que, no mesmo código, existem outros dois princípios fundamentais, que também regem a prática de sua profissão, conforme reproduzido a seguir (Conselho Federal de Psicologia, 2005):

I. O psicólogo baseará seu trabalho no respeito e na promoção da liberdade, da dignidade, da igualdade e da integridade do ser humano, apoiando-se nos valores que embasam a declaração universal dos direitos humanos.
II. O psicólogo trabalhará visando promover a saúde e a qualidade de vida das pessoas e das coletividades e contribuirá para a eliminação de quaisquer formas de negligência, violência, crueldade, opressão.

Ora, ao esquecer estes dois princípios, este/esta psicólogo/a age como aquela observador/as que, ao se deparar com as retas de Müller-Lyer, concentra-se apenas nas duas linhas centrais da figura, desprezando o efeito fundamental das setas que estão em suas extremidades. Ocorre que, ao fazer isso, exclui justamente a dimensão do mundo da vida da pessoa, desqualificando suas crenças. Sua atitude, então, não será a de "induzir" uma convicção religiosa, mas a de rejeitar algo central na vida daquelas pessoas religiosas e da própria sociedade ou comunidade onde está inserida. Este psicólogo/a, conforme o ressalta Neubern (2012), ao agir assim, estará trabalhando contrariamente à sua integridade subjetiva e a seus direitos como pessoa e cidadã.

Neubern (2013) aponta ainda que, enquanto nas ciências humanas, de um modo geral, a experiência religiosa era reduzida a outras dimensões, como a luta de classes ou as estratégias de poder e dominação, na psicologia, a redução tendia a se restringir a relação entre funções psíquicas ou a uma perspectiva psicopatológica. Sendo assim, considera que o que o/a psicólogo/a, que age como ilustrado no parágrafo anterior, parece não conseguir vislumbrar é que tais explicações, mesmo que pertinentes em alguns momentos, geralmente estão longe dos sentidos subjetivos ligados ao sagrado para aquelas pessoas, num distanciamento tão grande quanto ao mundo de suas experiências que a relação terapêutica pode se tornar irremediavelmente comprometida.

Deste modo, o/a clínico/a imbuído/a de uma perspectiva empática compreenderá as experiências religiosas de Yokaanam não simplesmente pela sua forma ou seu conteúdo, que se assemelham ao delírio religioso, ou pelos discursos de poder que vigoram no ocidente, como a noção de juízo, que tendem a dicotomizar as percepções humanas entre falsas e verdadeiras. Em vez disso, ele poderá olhar para elas como intrínsecas à sua própria história de vida e, nesta, ao seu destino vivido como profético, comportando sentidos fundamentais em seu contexto e junto aos que o cercam. Estes sentidos fundamentais não podem ser simplesmente reduzidos a categorias psiquiatrizantes em nome de um suposto saber científico, a preço de ocultar aquilo que ressalta aos olhos atentos e sensíveis ao mundo da vida.

Afinal, se o destino dado a Yokaanam tivesse sido determinado a partir do diagnóstico psiquiátrico, seu enquadramento em uma patologia ou quadro clínico clássico de paranoia, por exemplo, teria modificado completamente seu destino. Deste modo, então, os arredores de Brasília e os brasileiros em geral não teriam, em sua história, uma comunidade religiosa chamada Cidade Eclética, onde muitas pessoas encontraram e ainda têm encontrado sen- 
tidos para suas vidas. E em vez de Mestre, ele teria sido internado num hospital psiquiátrico, desprovido de seus direitos de ir e vir, condenado a tratamento medicamentoso provavelmente pelo resto de sua vida. Perguntemo-nos: a quem interessaria este outro destino?

\section{Considerações finais}

A título de considerações finais, retomemos com Husserl (1931/2001) a noção de Lebenswelt, a qual pretendia significar a experiência vivida, geralmente excluída pelas investigações das ciências naturais. O filósofo diz que este "mundo da vida" não é suficientemente universal e abstrato para servir de princípio e não é suficientemente concreto para servir ao mundo histórico, mas ao mesmo tempo é fundamentação axiológica de qualquer conhecimento elaborado nele e acerca dele. A tentativa de conciliar esses dois elementos representou para Husserl um paradoxo. E parece que não só para ele, mas também para aqueles que fazem ciência humana e a praticam na clínica cotidiana.

Este paradoxo com que Husserl se defrontava reflete em diagnósticos como aquele que foi dado a Yokaanam pela psiquiatria, pois por mais que hajam pensamentos e comportamentos que possam levá-lo à aproximação do modo de funcionamento paranóide, há que se considerar aquilo que representou sua experiência para ele, assim como também seus efeitos no mundo da vida, para ele e muitos fiéis. Se uma perspectiva hermenêutica se faz necessária para evitar-se o relativismo absoluto ou os riscos de fiar-se numa descrição meramente ingênua da realidade, ela também não se pode dar ao preço de uma interpretação apressada e comprometida apenas com a categorização da experiência humana.

Sabemos que o diagnóstico médico dá direção e conduz o tratamento, e neste sentido reconhecemos sua importância. Ele nos serve de guia ou mapa para tomar decisões importantes, como por exemplo, sobre a necessidade de medicação ou não. Mas fechá-lo numa pessoa que é singular e em constante processo de transformação, acaba sendo problemático, sobretudo quando nos deparamos com fenômenos que são poucos claros pelo discurso científico, como o são aqueles de ordem religiosa ou espiritual. Isso não significa, necessariamente, cair num relativismo total quanto à possibilidade de distinção entre o que é patológico e o que é religioso, mas implica em ampliar, significativamente, os critérios empregados para esta distinção. Significa também questionar os modelos dicotômicos, que defendem uma espécie de assepsia absoluta entre uma coisa e outra, como se a própria patologia não pude comportar experiência religiosa ou vice-versa. Significa, ainda, tecer uma reflexão suficientemente crítica para reconhecer que estas categorizações estão sempre contextualizadas historicamente. Para ilustrar este aspecto, basta lembrar que se, em W. James (1902/1995), o tronco tomado para análise do que era ou não saudável foi a própria experiência religiosa, cerca de 100 anos depois, com frequência, o tronco tomado para esta análise é a própria patologia, como se vê, por exemplo, em Jackson e Fulford (1997).

Por último, ressaltamos que vemos o esforço da psiquiatria em fazer um exame cuidadoso dos casos em que fenômenos místicos se entrecruzam com os psicóticos. Mas sabemos que temos muito a avançar no modo de olhar e tratar fenômenos desta ordem e este avanço implica também no retorno aos fundamentos em que esta nossa ciência foi se constituindo. Pensamos que um retorno às coisas mesmas, no sentido em que apontou Husserl, seria, então, o primeiro passo para tanto, sob pena que acreditarmos eternamente, no âmbito de nossa racionalidade, que as retas de Müller-Lyer são simplesmente iguais, a despeito de conservarmos em nós mesmos, também eternamente - no nível da primeira impressão, de cunho visceral, que elas são desiguais.

\section{Referências}

Aletti, M. (2012). A psicologia diante da religião e da espiritualidade: Questões de conteúdo e de método. Em M. H. Freitas \& J. G. Paiva (Orgs.). Religiosidade e cultura contemporânea (p. 157-190). Brasília: Universa.

Amatuzzi, M. M. (2001). Esboço de teoria do desenvolvimento religioso. Em J. G. Paiva (Org.). Entre necessidade e desejo: diálogos da psicologia com a religião (p. 25-51). São Paulo: Loyola.

Araújo, D. N. (2009). Um líder messiânico em terras do planalto central. Revista caminhos da história, 5(2). Recuperado em Setembro de 2013, de http://www.uss.br/pages/revistas/ revistacaminhosdahistoria/revistahistoria2009-2/revistaeletronica/arquivos/Artigo_Daniela_Nunes.pdf

Baltazar, D. V. S. (2003). Crenças religiosas no contexto dos projetos terapêuticos em saúde mental: Impasse ou possibilidade? (Dissertação de Mestrado). Escola Nacional de Saúde Pública da Fundação Oswaldo Cruz, Ministério da Saúde, Manguinhos.

Bello, A. (1998). Culturas e religiões: uma visão fenomenológica. (A. Angonese Trad.) São Paulo: Edusc.

Bello, A. A. (2000). Edmund Husserl (1859-1938) - Teleo-logia e teo-logia. Em G. Penzo \& R. Gibellini, Deus na filosofia do século XX. (R. L. Ferreira, Trad.), (p. 65-74). São Paulo: Loyola. (Trabalho original publicado em 1993)

Carrette, J. R. (2004). The return to James: Psychology, religion and the amnesia of Neuroscience. Em W. James, Varieties of religious experience: A study in human nature (p. xxxixl-lxiii), Centenary Edition. London and New York: Routledge. (Obra de James originalmente publicada em 1902 e introdução de Carrete ao centenário da Obra originalmente publicado em 2002). 
Carrette, J. R. (2013). Foundations, power and criticism: rethinking the Psychology of Religion with William James. Em M. H. Freitas; G. J. Paiva \& C. Moraes, Psicologia da Religião no mundo ocidental contemporâneo: desafios da interdisciplinaridade (p. 51-88). Brasília: Universa.

Cerqueira, S. B. (2014). Conteúdos messiânicos milenaristas nos movimentos pentecostais e neopentecostais. Revista observatório da religião, 1. Recuperado em outubro de 2013, de: file://C:/Users/ml/Downloads/307-607-1-PB.pdf>.

Conselho Federal de Psicologia (2005). Código de Ética Profissional do Psicólogo. Brasília, DF.

Cipriano, J. R. (2005). Cidade eclética: messianismo, carisma e rotinização. (Dissertação de Mestrado). Universidade Federal de Goiás, Goiânia.

Freitas, M. H. (2012). Religiosidade na experiência de atuação psi: sintoma ou saúde? Em M. H. Freitas \& G. J. Paiva (Orgs.). Religiosidade e cultura contemporânea: desafios para a Psicologia (p. 191-230). Brasília: Universa.

Freitas, M. H. (2013). Religiosidade e saúde mental em imigrantes: a percepção de psiquiatras e psicólogos ingleses e brasileiros. Em M. H. Freitas; G. J. Paiva \& C. Moraes (Orgs.). Psicologia da Religião no mundo ocidental contemporâneo: desafios da interdisciplinaridade (p. 257-274). Brasília: Universa.

Freitas, M. H. (2015). Manejo da religiosidade nos contextos de saúde: a experiência de psicólogos/as [Resumo Estendido]. In GT Psicologia \& Religião da Associação Nacional de Pesquisa e Pós-Graduação em Psicologia (ANPEPP) \& PUCPR (Org.). Anais do X Seminário de Psicologia \& Senso Religioso, 10. Curitiba: PUCPR. Recuperado em julho de 2016 de: $<$ http://www2.pucpr.br/reol/pb/index.php/spsr?dd99=anais >

Husserl, E. (2000). A idéia da fenomenologia. Lisboa / Portugal: Edições 70. (Originalmente publicado em 1950).

Husserl, E. (2008). A crise da humanidade européia e a Filosofia. Covilhã: LusoSofia. (Originalmente publicado em 1936).

Husserl, E. (2001) Meditações cartesianas: Introdução a fenomenologia. (F. Oliveira, Trad.) São Paulo: Madras. (Originalmente publicado em 1931)

Jackson, M. \& Fulford, K. W. M. (1997). Spiritual experience and psychopathology. Em K. W. M. Fulford \& J. Z. Sadler. Philosophy, Psychiatry \& Psychology, 4(1): 2-26.

James, W. (1995). As variedades da experiência religiosa: um estudo sobre a natureza humana. (O. M. Cajado, Trad.). São Paulo: Cultrix. (Originalmente publicado em 1902).

Jaspers, K. (1979). Psicopatologia geral: Psicologia compreensiva, explicativa e fenomenologia, 1. Rio de Janeiro: Livraria Atheneu. (Originalmente publicado em 1913).

Leibniz, G. W. (1979). A monadologia. (M. Chaú́ Trad.). São Paulo: Abril Cultural. (Originalmente publicado em 1714).

Mello, G. B. R. (2004). Os peregrinos ecléticos cristãos. Cadernos de campo, 12, 25-40. Recuperado em Setembro de 2013, de file://C:/Users/ml/Downloads/53884-67606-1-SM.pdf
Merleau-Ponty, M. (1999). Fenomenologia da percepção. (C. A. R. Moura, Trad.). São Paulo: Martins Fontes. (Originalmente publicado em 1945).

Mira y López, E. (1957). Psiquiatria, 2. Rio de Janeiro: Editora Científica.

Negrão, L. N. (2001). Revisitando o messianismo no Brasil e profetizando seu futuro. Revista brasileira de ciências sociais, 16(46). Recuperado em Setembro de 2013, de: <http://www. scielo.br/pdf/rbcsoc/v16n46/a06v1646.pdf>.

Neubern, M. (2013). O que significa acolher a espiritualidade do outro? Considerações de uma clínica ethnopsy. Em M. H. Freitas, G. J. Paiva \& Moraes, C. (Orgs.) Psicologia da Religião no mundo ocidental contemporâneo: desafios da interdisciplinaridade (p. 145-183). Brasília: Universa.

Valle, E. (1998). Psicologia e experiência religiosa. São Paulo: Loyola.

Vergote, A. (1969). Psicologia religiosa. (Versão española de M. H. Miñon.). Madrid: Taurus.

Vergote, A. (1998). Culpa e deseo. Dos ejes cristianos y la desviación patológica. Peru: Fondo de Cultura Económica. (Originalmente publicado em 1978).

Vilela, P. R. (2015). A experiência religiosa de Yokaanam no contexto da saúde mental: uma leitura fenomenológica. (Dissertação de Mestrado). Universidade Católica de Brasília, Brasília.

Vilela, P. R. \& Freitas, M. H. (2016). Saúde mental, religiosidade, psicodiagnóstico e dignidade humana: o caso Youkaanam. Em L. C. L. Tomaz \& R. A. F. Tomaz, Dignidade da pessoa humana: temas contemporâneos. Uberlândia: Composer.

Wittgenstein, L. (1968). Tractatus logico-philosophicus. (J. A. Giannotti, Trad.). São Paulo: Nacional/USP. (Trabalho original publicado em 1921).

Yokaanam. (Versão 2011). Entre apupos e homenagens. Elpídio (Org.). Santo Antônio do Descoberto, GO: Editora Jornal O Nosso.

Marta Helena de Freitas - Doutora em Psicologia pela Universidade de Brasília, com Pós-Doutoramento no Department of Religious Studies, School of European Culture and Languages, University of Kent at Canterbury, UK e pelo Programa Doutoral em Psicologia da Faculdade de Psicologia e Ciências da Educação da Universidade do Porto, Portugal. Endereço Institucional: Universidade Católica de Brasília, Pró-Reitoria de Pós-Graduação e Pesquisa, Mestrado Em Psicologia. SGAN 916, Módulo B, W5 Norte Asa Norte. CEP: 70.790-160. E-mail: mhelenadefreitas@gmail.com

Paula Rey Vilela - Graduada em Psicologia pela Universidade do Estado de Minas Gerais e Mestre em Psicologia, pela Universidade Católica de Brasília. E-mail: paulareyvilela@gmail.com

Recebido em 14.07.2016 Primeira Decisão Editorial em 05.09.2016 Aceito em 08.12.2016 